\title{
Pengembangan Sistem Informasi Administrasi Penyerapan Anggaran Penyelidikan
}

\author{
Parlia Romadiana \\ STMIK Atma Luhur \\ Jl. Jenderal Sudirman, Kel. Selindung, Kec. Gabek Pangkalpinang \\ Telp. (0717) 433506 \\ parliaromadiana@atmaluhur.ac.id
}

\begin{abstract}
Abstrak- Administrasi penyerapan anggaran penyelidikan di Subdit III masih dilakukan secara manual dalam hal pengolahan data sehingga membutuhkan waktu yang lama dalam hal pembuatan administrasi dan mengakses data, menyulitkan dalam mengontrol kelebihan penggunaan anggaran penyelidikan sehingga mengakibatkan adanya temuan saat pemeriksaan dan membutuhkan waktu yang lama dalam hal pembuatan laporan penyerapan anggaran penyelidikan.Sistem informasi administrasi penyerapan anggaran penyelidikan dirancang dengan menggunakan unified modelling languange untuk mengatasi permasalahan diatas agar dapat membantu di Subdit III Tipidkor dalam hal pengolahan data administrasi penyerapan anggaran penyelidikan sehingga dapat memudahkan dalam hal pembuatan administrasi penyerapan anggaran penyelidikan, memudahkan mengontrol kelebihan penggunaan angaran penyelidikan dan menghasilkan laporan yang cepat, tepat dan valid.
\end{abstract}

Kata Kunci: Sistem Informasi, Penyerapan Anggaran, Unified Modelling Languange.

\section{PENDAHULUAN}

Sistem kinerja yang baik, efektif dan efisien bagi suatu instansi dapat dihasilkan jika instansi mempunyai sumber daya manusia yang profesional dan sumber daya lainnya yang mendukung kinerja instansi tersebut yaitu teknologi dan sistem informasi dalam hal pengolahan data. Pengolahan data yang baik sangat diperlukan bagi suatu instansi agar dapat memudahkan proses pekerjaan di instansi tersebut dalam memberikan suatu informasi yang akurat kepada pimpinan, termasuk dalam hal pengolahan data penyerapan anggaran. Administrasi proses penyerapan anggaran penyelidikan tindak pidana korupsi yang baik sangat penting untuk mendukung proses pencairan anggaran. Administrasi penyerapan anggaran penyelidikan tindak pidana korupsi dimulai dari proses pembuatan rencana penyerapan anggaran, pembuatan laporan hasil pelaksanaan tugas penyelidikan, pembuatan rincian kelebihan dan kekurangan anggaran yang telah digunakan, dan pembuatan laporan penyerapan anggaran penyelidikan. Administrasi penyerapan anggaran penyelidikan dibuat oleh BANIT, sehingga berkas-berkas penyerapan anggaran penyelidikan disimpan oleh masing-masing BANIT yang membuat administrasi tersebut. Hal ini menyulitkan Staf BANUM dalam pembuatan laporan karena kesulitan dalam mengakses berkas-berkas yang diperlukan dalam pembuatan laporan penyerapan anggaran penyelidikan sehingga staf BANUM harus mengumpulkan berkas dari setiap BANIT yang melakukan penyerapan anggaran penyelidikan. Hal tersebut menghasilkan ketidakefektifan dan efisiensi kerja dalam proses pengolahan administrasi penyerapan anggaran penyelidikan. Oleh karena itu, administrasi penyerapan anggaran penyelidikan harus dikelola oleh satu orang yang bertanggung jawab mengelola administrasi penyerapan anggaran penyelidikan sehingga mudah dalam mengakses data yang diperlukan dalam pembuatan laporan agar laporan yang dihasilkan menjadi akurat dan meminimalisir resiko kehilangan data.

Berdasarkan permasalahan diatas, penulis ingin mengembangkan sistem informasi administrasi penyerapan anggaran yang dapat Memberikan kemudahan dalam proses administrasi penyerapan anggaran dengan menerapkan model UML.

\section{LANDASAN TEORI}

\section{A. Unified Modelling Languange}

Unified Modelling Language (UML) adalah sebuah "bahasa" yang telah menjadi standar dalam industri untuk visualisasi, merancang dan mendokumentasikan sistem piranti lunak. UML menawarkan sebuah standar untuk merancang model sebuah sistem. Dengan menggunakan UML kita dapat membuat model untuk semua jenis aplikasi piranti lunak, dimana aplikasi tersebut dapat berjalan pada piranti keras, sistem operasi danjaringan apapun, serta ditulis dalam bahasa pemrograman apapun. Tetapi karena UML juga menggunakan class dan operation dalam konsep dasarnya, maka ia lebih cocok untuk penulisan piranti lunak dalam bahasa-bahasa berorientasi obyek. Notasi UML terutama diturunkan dari 3 notasi yang telah ada sebelumnya : Grady Booch OOD (Object-Oriented Design), Jim Rumbaugh OMT (Object Modelling Technique), dan Ivar Jacobson OOSE (Object-Oriented Software Engineering).

Cakupan UML diantaranya : Pertama, UML menggabungkan konsep BOOCH, OMT, dan OOSE, sehingga UML merupakan suatu bahasa permodelan tunggal yang umum dan digunakan secara luas oleh para user ketiga 
metode tersebut dan bahkan para user metode lainnya. Kedua, UML menekankan pada apa yang dapat dikerjakan dengan metode-metode tersebut. Ketiga, UML berfokus pada suatu bahasa permodelan standar, bukan pada proses standar [1].

\section{B. Teori Penyerapan Anggaran}

Anggaran adalah pernyataan yang terkuantifikasi dan tertulis dari rencana manajemen[2]. Manfaat anggaran antara lain :

1. Anggaran merupakan alat komunikasi bagi rencana manajemen melalui organisasi.

2. Anggaran memaksa manajer untuk memikirkan dan merencanakan masa depan.

3. Proses penganggaran merupakan alat alokasi sumber daya pada berbagai bagian dari organisasi agar dapat digunakan seefektif mungkin.

4. Anggaran mengkoordinasikan aktivitas seluruh organisasi dengan cara mengintegrasikan rencana dari berbagai bagian penganggaran ikut memastikan agar setiap orang dalam organisasi mengarah pada sasaran yang sama.

5. Anggaran menentukan tujuan dan sasaran yang dapat berlaku sebagai benchmark untuk mengevaluasi kinerja pada waktu berikutnya.

\section{Tinjauan Studi}

Tabel 1. Tinjauan Studi

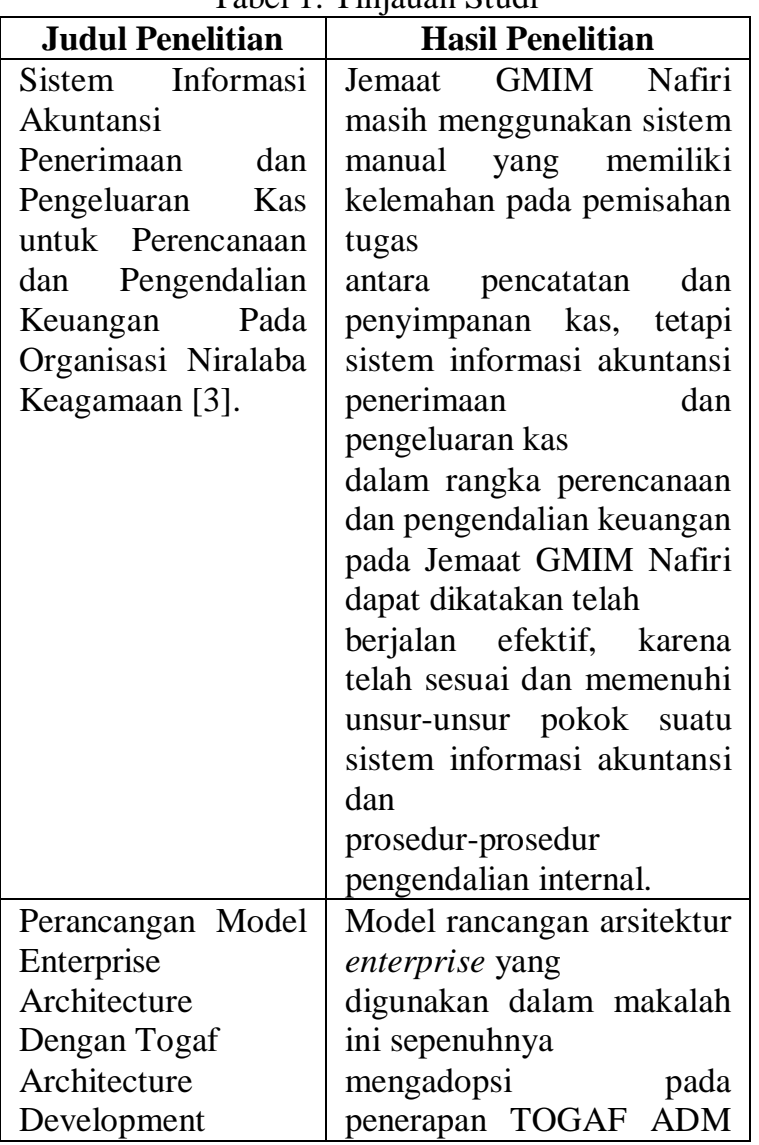

\begin{tabular}{|c|c|}
\hline Method[4]. & 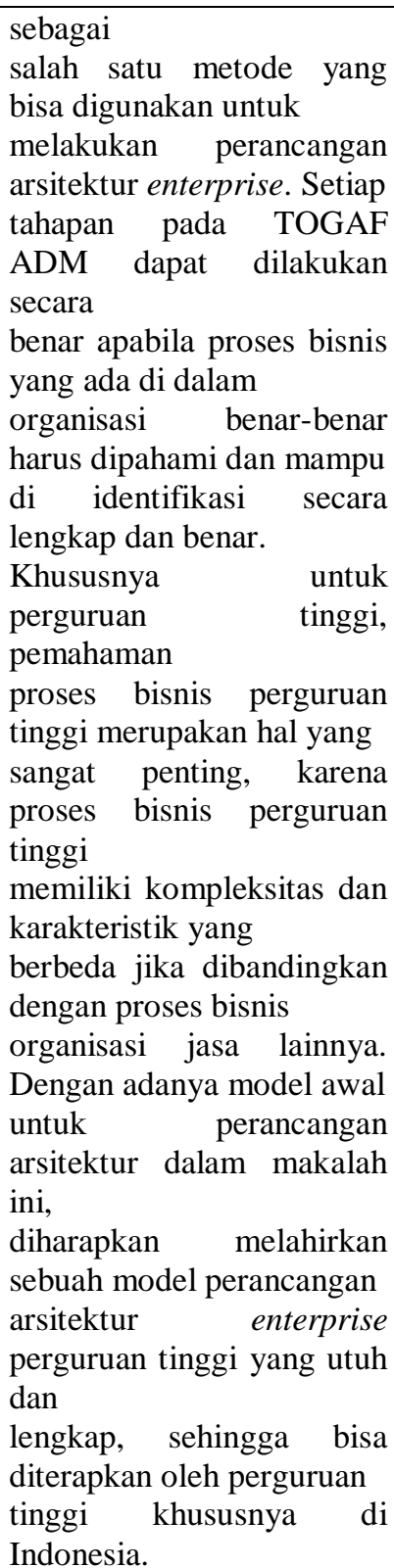 \\
\hline $\begin{array}{l}\text { Analisis dan Desain } \\
\text { Sistem Informasi } \\
\text { Akuntansi Pada } \\
\text { Usaha Kecil dan } \\
\text { Menengah (Studi } \\
\text { Kasus pada CV. } \\
\text { Smart Teknologi } \\
\text { Indonesia)[5]. }\end{array}$ & $\begin{array}{lr}\text { Rancangan } & \text { sistem } \\
\text { informasi akuntansi sesuai } \\
\text { dengan kebutuhan CV, } \\
\text { Smart Teknologi Indonesia } \\
\text { dimana dapat memberikan } \\
\text { kenyamanan dalam catatan, } \\
\text { perhitungan, dan } \\
\text { menghasilkan laporan } \\
\text { keuangan secara cepat, } \\
\text { tepat dan akurat. }\end{array}$ \\
\hline
\end{tabular}




\section{Metode PENELITIAN}

Metode penelitian yang penulis gunakan dalam merancang Sistem Informasi Penyerapan Anggaran Penyelidikan yaitu sebagai berikut :

A. Analisa Masalah dan Studi Kelayakan

Pada tahap ini penulis melakukan pengumpulan data dengan cara sebagai berikut :

1. Riset Lapangan

Penulis melakukan pengumpulan data dengan melakukan riset secara langsung di SUBDIT III tipidkor dengan cara sebagai berikut :

a) Wawancara (Interview)

Penulis melakukan wawancara dengan teknik Tanya jawab kepada pihak-pihak yang terlibat dalam rangka mendapatkan data dan informasi.

b) Pengamatan (Observasi)

Penulis melakukan pengamatan secara langsung di SUBDIT III tipidkor untuk mengetahui proses-proses yang dilakukan dalam penyerapan anggaran penyelidikan tipidkor.

2. Riset Kepustakaan

Penulis juga mencari data dan informasi yang berhubungan dengan masalah yang dibahas , melalui buku-buku ilmiah, diktat dan bahan-bahan kuliah serta tulisan-tulisan yang berhubungan dengan penelitian ini.

\section{B. Analisa Sistem}

Kegiatan yang dilakukan dalam tahapan ini adalah sebagai berikut:

1) Menganalisa sistem berjalan, yaitu mempelajari dan mengetahui apa yang dilakukan oleh sistem yang ada.

2) Menspesifikasikan sistem berjalan, yaitu menspesifikasikan masukan yang ada, proses yang dilakukan dan keluaran yang dihasilkan.

Adapun tools yang digunakan dalam menganalisa sistem antara lain :

1) Activity Diagram

Activity Diagram digunakan untuk memodelkan alur kerja (workflow) dari sebuah proses bisnis dengan urutan serangkaian aktifitas didalam perusahaan

Use Case Diagram

Use Case Diagram digunakan untuk menggambarkan antara use case dengan actor tanpa mendeskripsikan bagaimana aktifitasaktifitas tersebut diimplementasikan.

2) Deskripsi Use Case

Deskripsi Use Case digunakan untuk menjelaskan fungsi dasar dari sistem, bagaimana sistem dijalankan oleh user dan bagaimana sistem merespon tindakan user.

\section{Rancangan Sistem}

Tahap perancangan sistem adalah merancang sistem secara rinci berdasarkan hasil analisa sistem berjalan yang telah dilakukan, sehingga menghasilkan model sistem baru yang diusulkan, dengan disertai rancangan database dan spesifikasi program.

Adapun tools yang digunakan dalam tahapan ini antara lain :

1) ERD (Entity Relationship Diagram)

Entity Relationship Diagram digunakan untuk mempresentasikan hubungan yang terjadi antara satu atau lebih komponen.

2) LRS (Logical Record Structure)

Logical Record Structure Terdiri dari link-link diantara tipe record. Link ini menunjukkan arah dari satu tipe record lainnya.

3) Spesifikasi Basis Data

Spesifikasi Basis Data digunakan untuk menjelaskan tipe data secara detail.

4) Sequence Diagram

Sequence Diagram menunjukkan secara detail bagaimana objek saling berhubungan satu sama lain dari waktu ke waktu.

\section{HASIL DAN PEMBAHASAN}

\section{A. Proses Bisnis Berjalan}

Adapun proses binis dalam penyerapan anggaran dimulai dari kanit memerintahkan banit untuk membuat ren lidik dan nota dinas pengajuan ren lidik (nd pengajuan ren lidik) lalu banit menanyakan data untuk pembuatan ren lidik, lalu kanit mengkonfirmasi data untuk pembuatan ren lidik, kemudian banit membuat ren lidik dan nd pengajuan ren lidik. banit mengecek penanggungjawab kegiatan, jika yang bertanggung jawab kanit, maka banit menyerahkan ren lidik kepada kanit untuk ditandatangani lalu kanit menandatangani dan menyerahkan kepada banit. jika yang bertanggung jawab panit maka banit menyerahkan kepada panit untuk ditandatangani dan panit menandatangani lalu menyerahkan kepada banit. lalu banit menyerahkan nd pengajuan ren lidik dan ren lidik kepada kasubdit untuk ditandatangani lalu kasubdit menandatangani nd pengajuan ren lidik dan ren lidik. kemudian banit meregister nd pengajuan ren lidik tersebut ke dalam buku nota dinas keluar. banit mengajukan nd pengajuan ren lidik beserta ren lidik kepada direktur.

Proses bisnis berjalan digambarkan dalam activity diagram sebagai berikut: 
Jurnal SISFOKOM, Volume 07, Nomor 01, Maret 2018

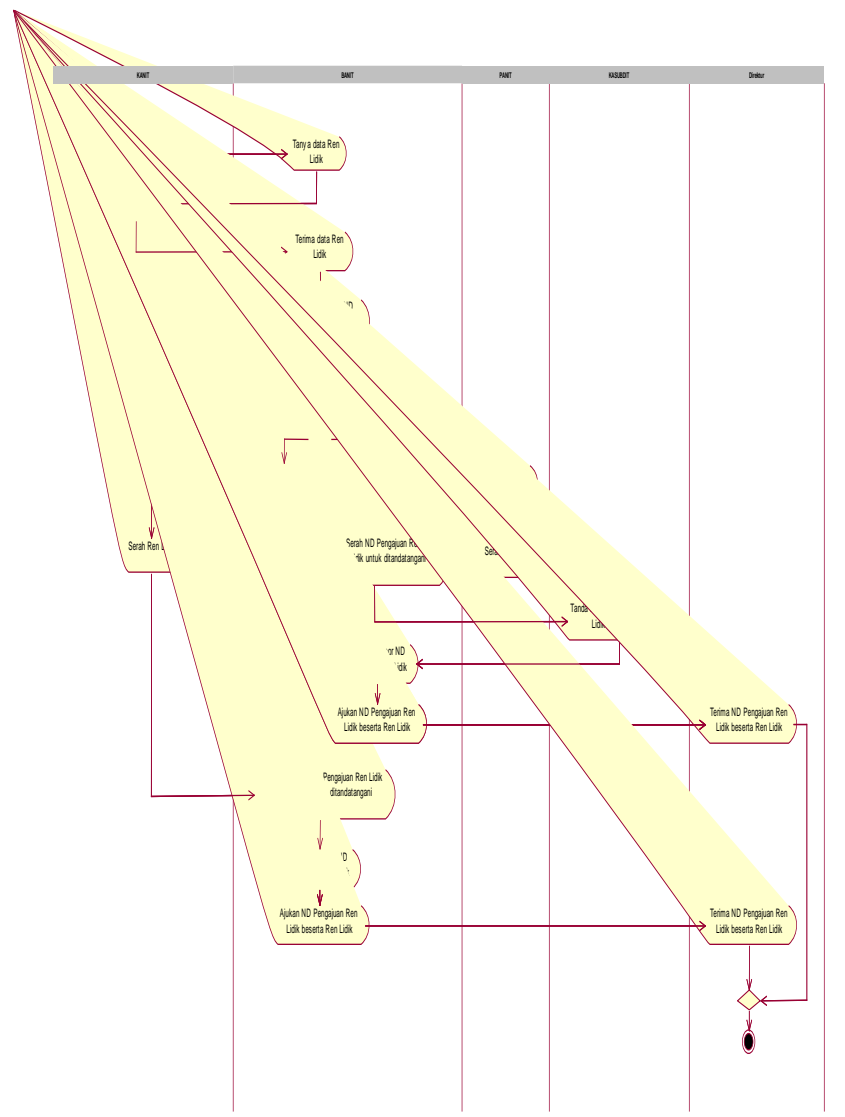

Gambar 1. Activity Diagram

B. Package Diagram

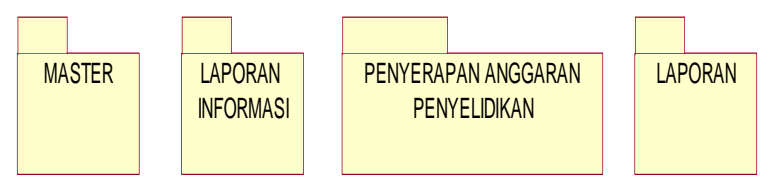

Gambar 1. Package Diagram

C. Use Case Diagram

1) Use Case Diagram Master

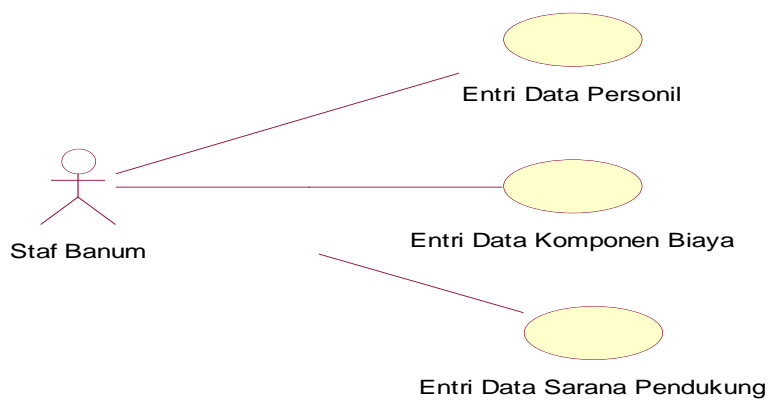

Gambar 3. Use Case Diagram Master
2) Use Case Diagram Laporan Informasi

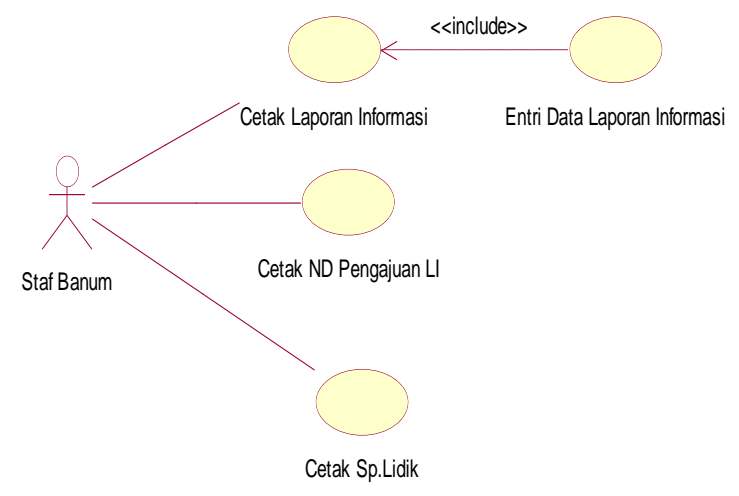

Gambar 4. Use Case Diagram Laporan Informasi

3) Use Case Diagram Penyerapan Anggaran

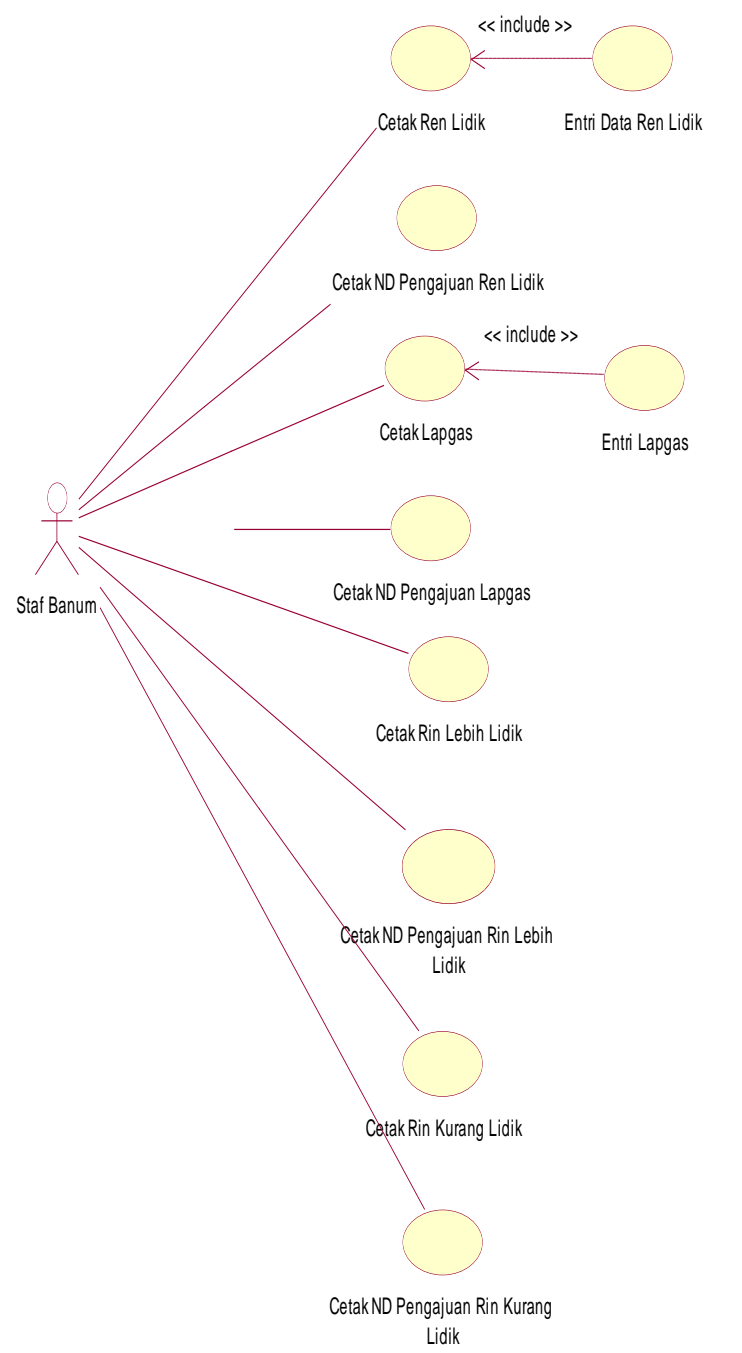

Gambar 5. Use Case Diagram Penyerapan Anggaran 
4) Use Case Diagram Laporan

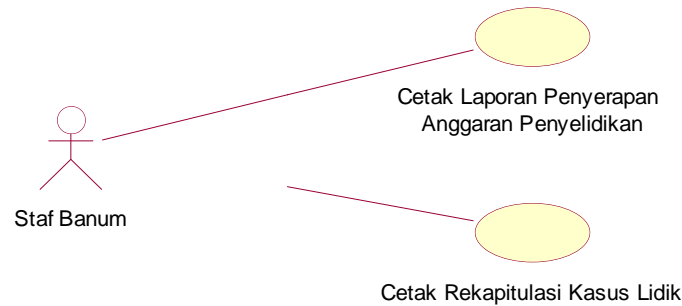

Gambar 6. Use Case Diagram Laporan

D. Rancangan Basis Data

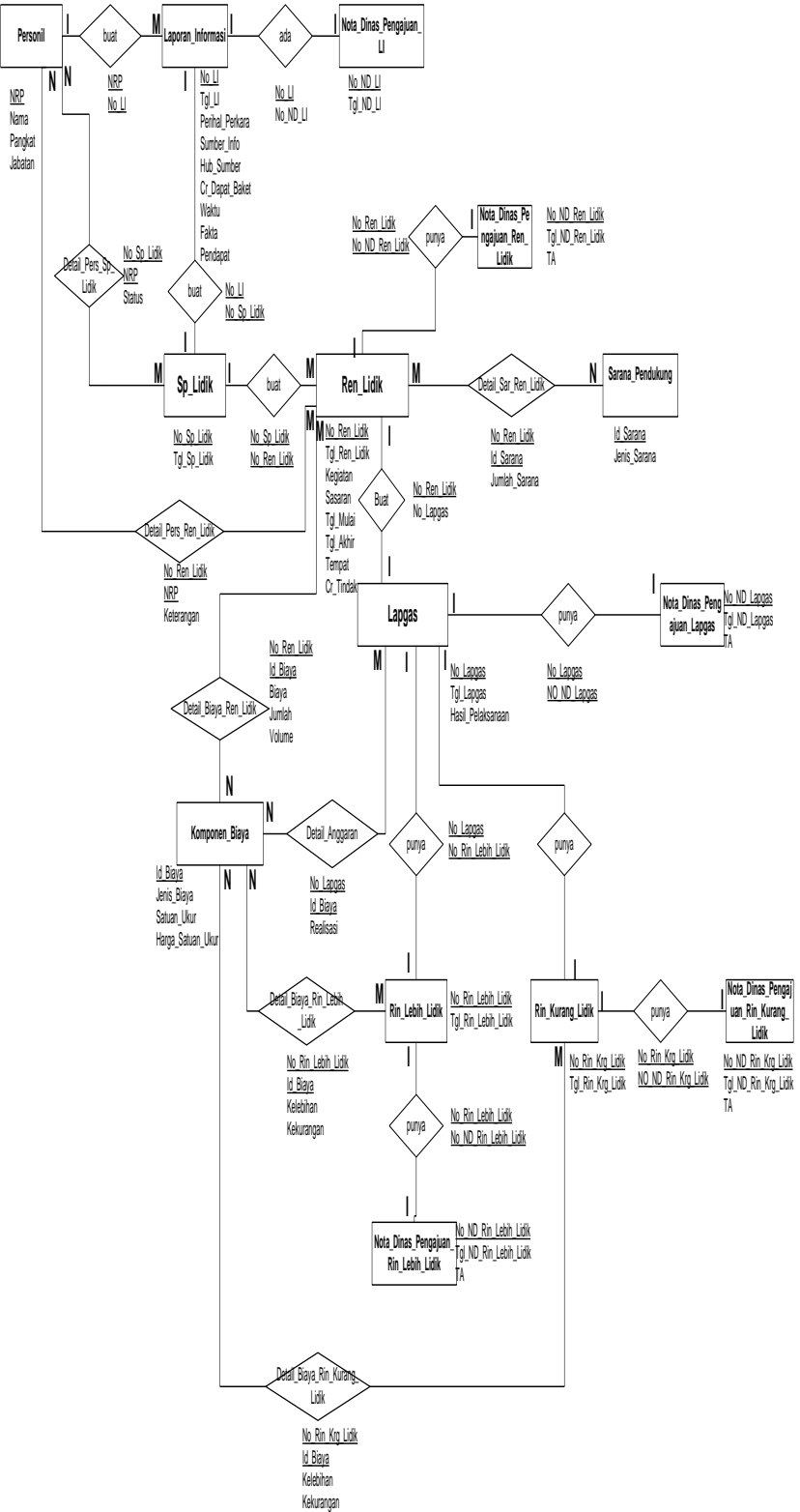

Jurnal SISFOKOM, Volume 07, Nomor 01, Maret 2018

E. Struktur Tampilan

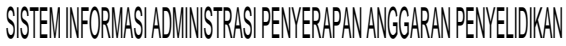
DI SUBOT II TPPDKOR DT RESKRINSUSP POLDAKEP, BABELL

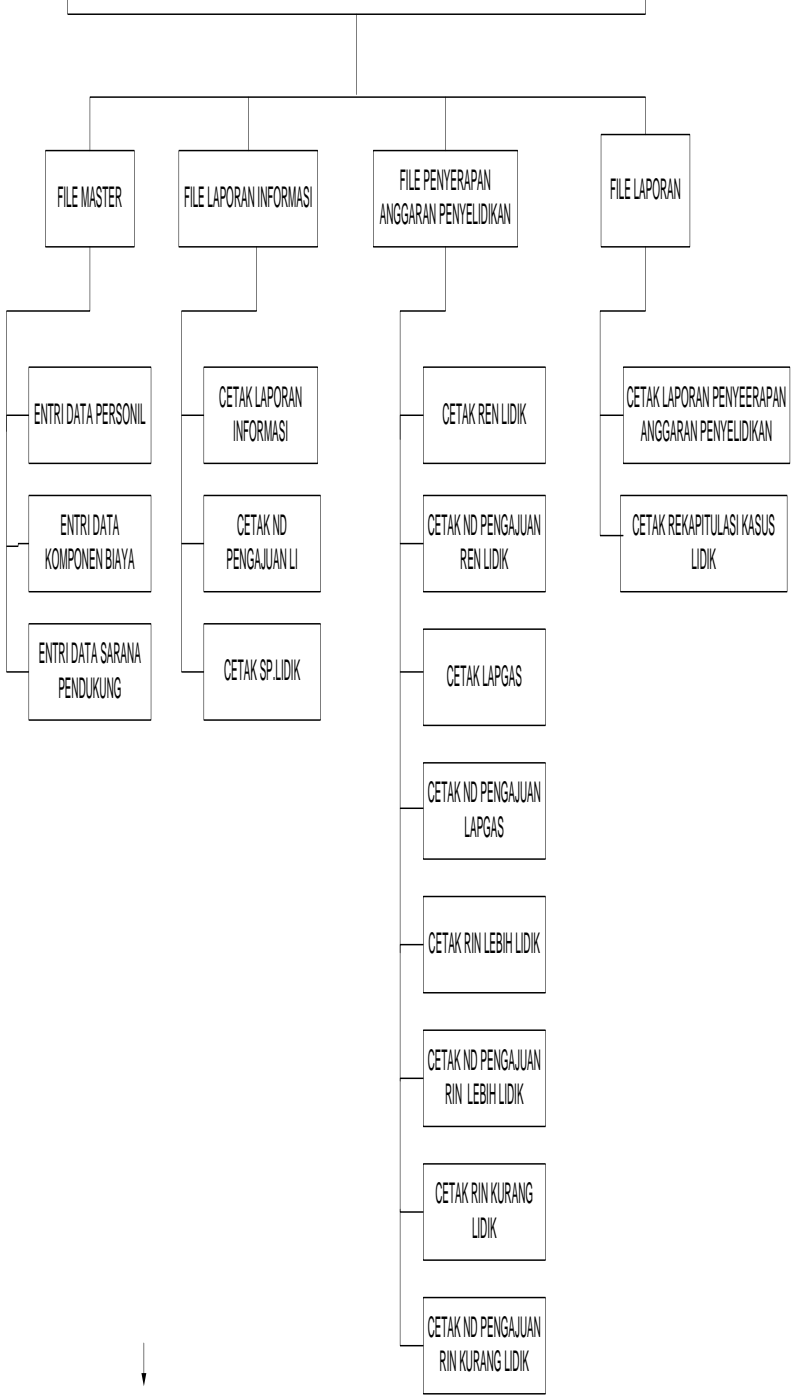

Gambar 8. Struktur Tampilan

Gambar 7. Entity Relationship Diagram 


\section{F. Implementasi}

CETAKRENCANA ANGGARAN PENYELIDKAN
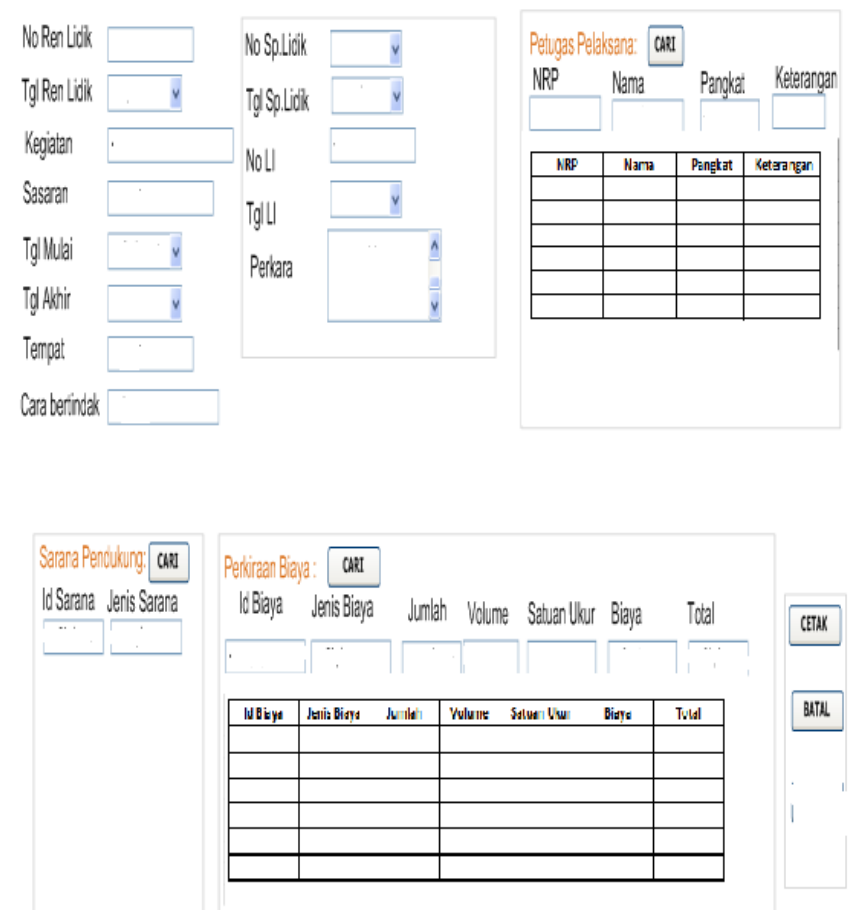

Gambar 9. Implementasi

\section{PENUTUP}

\section{A. Kesimpulan}

Setelah mempelajari permasalahan yang dihadapi dan solusi pemecahan masalah yang diusulkan, maka ditarik kesimpulan sebagai berikut:

a. Dengan menggunakan sistem informasi administrasi penyerapan anggaran penyelidikan, proses pembuatan administrasi penyerapan anggaran penyelidikan akan menjadi lebih cepat karena semua proses telah terkomputerisasi.

b. Dengan adanya sistem informasi administrasi penyerapan anggaran penyelidikan, kelebihan penggunaan anggaran lebih mudah dikontrol sehingga tidak menjadi temuan ketika ada pemeriksaan.

c. Dengan menggunakan sistem informasi administrasi penyerapan anggaran penyelidikan, data-data penyerapan anggaran penyelidikan lebih aman tersimpan dan mudah untuk diakses sehingga membutuhkan waktu yang cepat untuk mengakses data.

d. Perancangan sistem informasi berorientasi objek (Object Oriented) dapat menghasilkan sistem informasi yang lebih baik dan lebih mudah dipahami dalam hal struktur perancangannya.

\section{B. Saran}

Adapun beberapa saran yang dikemukakan adalah sebagai berikut:

a. Dengan adanya sistem informasi, maka disarankan adanya pengembangan lebih lanjut untuk merancang sistem yang lebih baik dan kompleks sesuai dengan kebutuhan.

b. Perlu adanya peningkatan infrastruktur komputer agar dapat terciptanya efisiensi dan efektivitas dalam rangka mendukung sistem informasi ini.

c. Adanya pelatihan kepada user yang akan menggunakan sistem informasi administrasi penyerapan anggaran penyelidikan agar user dapat mengetahui bagaimana cara menggunakan dan perawatan sistem informasi ini.

d. Adanya perguliran tugas administrasi penyerapan anggaran penyelidikan dimana disarankan agar Staf BANUM dapat manjadi user yang akan menggunakan sistem informasi administrasi penyerapan anggaran penyelidikan agar proses administrasi penyerapan anggaran penyelidikan menjadi efektif dan efisien.

e. Perlu dilakukan back-up dalam kurun waktu tertentu terhadap data-data untuk mengantisipasi kehilangan data.

f. Perlu adanya audit paling tidak setiap dua (2) tahun sekali pada sistem informasi ini untuk memperbaiki kesalahan-kesalahan yang terjadi pada sistem informasi yang terbaru dalam rangka mendukung sistem informasi ini.

\section{DAFTAR PUSTAKA}

[1] Munawar, Ahmad. 2005. Pemodelan Visual Dengan UML. Graha Ilmu, Jakarta.

[2] Http://id.wikipedia.org/wiki/Anggaran, diakses pada tanggal 15 Februari 2018

[3] Kabuhung, Merystika. 2015. Sistem Informasi Akuntansi Penerimaan dan Pengeluaran Kas untuk Perencanaan dan Pengendalian Keuangan Pada Organisasi Niralaba Keagamaan. Jurnal EMBA Vol.1 No.3 Juni 2013, Hal. 339-348.

[4] Surendro, Kridanto. Yunis, Roni. 2009. Perancangan Model Enterprise Architecture Dengan Togaf Architecture Development Method. Seminar Nasional Aplikasi Teknologi Informasi 2009 (SNATI 2009) ISSN: 1907-5022 Yogyakarta, 20 Juni 2009.

[5] Sularto, Lana. Rachman, Windy Atmawardani. Analisis dan Desai Sistem Informasi Akuntansi Pada Usaha Kecil dan Menengah (Studi Kasus pada CV. SMART TEKNOLOGI INDONESIA). Proceeding PESAT ISSN: 1858-2559 Universitas Gunadarma Vol 4 Oktober 2011. 